\title{
American Documentation
}

\section{Institute Meeting}

By PHYLLIS A. RICHMOND

$\mathrm{T}$ He anNual meEting of the American Documentation Institute was held October 22-24 at Lehigh University, Bethlehem, Pa. The registration for this meeting was 195, making it the largest to date. The program, built around the theme "Round-up of documentation experience in small collections- 50,000 documents or less," consisted of two sessions of invited papers on various aspects of this theme on the first day. The second day was reserved for volunteer papers. On the last day there was a panel discussion of the feasibility of applying experience gained in small systems to large systems.

Evaluation of documentation experience was made with respect to several pertinent questions: What kinds of systems have been used? What kind of informational material is indexed for storage in these systems? What significance does experience in small systems have in developing larger systems?

To answer the first question, four indexing systems were described: classifications, by Saul Herner; subject headings, by Marjorie R. Hyslop and Alan Rees; descriptors, by Claude W. Brenner; and Uniterms, by John C. Costello, Ir. Some very interesting factors were brought out in the papers and in the discussion that followed. The most interesting, perhaps, was the apparent underlying basic similarity of methods being developed in all four systems, despite great confusion in the terminology used in describing them. Subject headings, descriptors, and Uniterms-all sophisticated variations of alphabetical indexing -are more and more being forced to utilize some kind of classification (in-
Dr. Richmond is Continuations Cataloger, University of Rochester Library.

verted headings or "bound terms," if nothing else) in order to make a realistic representation of the subject matter being described, while classification cannot function without a detailed alphabetical index and concise terminology, though the latter does not have to be self-sufficient to the degree necessary in subject headings, descriptors, or Uniterms.

Mr. Herner discussed classification concepts in simple terms, pointing out the significance of the rise of faceted classification, designed for specific user groups, as a "do-it-yourself" response to the failure of major general classifications to supply sufficiently detailed schedules for specialized parts of knowledge. He also reiterated the call for more research on user techniques in libraries, especially emphasizing the necessity for discovering what variations there are in approach among users in different subject fields and also among different groups in the same field.

Mrs. Hyslop and Mr. Rees discussed methods of making subject heading lists, from the simplest, which grow by expediency, to the most complex, where a definite pattern of analysis is established. Experiences in indexing American Society for Metals publications over the past twenty years were used in illustration, and the present project of compiling a subject authority list from the ASM-SLA metallurgical classification was outlined.

Descriptors, as enumerated by Claude

COLLEGE AND RESEARCH LIBRARIES 
Brenner, are a special indexing form in which the terms used are relatively broad in meaning and use as compared with either subject headings or Uniterms. Currently there are only about 250 descriptors in the dictionary, each very carefully selected and defined by experts in the fields to which they apply. The indexing system using this form recovers a broad spectrum of material relating to a subject, rather than relatively specific items as in other systems.

$\mathrm{Mr}$. Costello gave a very lucid history of Uniterms and their application to mechanical selection. The method described for eliminating false drops or "noise" by binding individual Uniterms to their role indicators (generic terms to indicate function), thus "tagging" individual meanings on a categorical basis (called "syntactical control") was especially striking. The importance of the thesaurus in Uniterms work was stressed. The $\mathrm{Du}$ Pont solution to the problem of accession listing or "posting" by using twentytwo-inch IBM cards sounded impressive.

In the discussion of these four papers the point was brought out again and again that it was rather difficult to distinguish among all the different words now being used for roughly the same idea: subject headings, descriptors, key words, Uniterms, Kros-Terms, etc. The audience was amused at one point by a plaintive query concerning "the pure Uniterms as they used to be or the cleaned-up Uniterms." The need for a common vocabulary was felt strongly.

The afternoon session on the evaluation of searching methods featured Eugene Garfield speaking on document card systems, Fred R. Whaley on index card systems, and Claire K. Schultz on the limits of mechanization in small systems. Both Mr. Garfield and Dr. Whaley compared document (direct) card systems, where every card in the file is scanned by machine in each search for specific information, with index term (inverted file) systems, where information is obtained by matching cards stored under pertinent subject terms to find common accession numbers, using only a part of the file in each search. Mr. Garfield used Shannon's formula for information content to outline his theoretical qualifications for an ideal document card system, while Dr. Whaley emphasized the deep indexing advantages to be found in the index term card system.

Mrs. Schultz, in dealing with the capabilities and limitations of information systems, pointed out that "the system with high input ${ }^{1}$ costs is likely to have low output ${ }^{2}$ costs and vice versa." This truism, amply illustrated by her excellent analysis of the basic problems of information storage and retrieval, and her delineation of the type of thing which now can be done by machine, shows that there is still no substitute for an intelligent cataloger (by whatever name he be called) at the input end; and further, that with the machines as servants the range of opportunity open to this cataloger for improving input quality, at least on the subject side, is going to increase greatly.

The thirteen volunteer papers dealt largely with topics related to the main theme of the conference. Space does not permit description of them, but the paper of Anne McCann and Mary Ellen Padin, "Conversion to Machine Punched Card Systems for Library Processing Operations: The Need for Analytical and Comparative Study," was probably most likely to interest librarians. The authors reported on IBM-machine-based methods of handling book acquisition, serials bibliography, and the routing of periodical literature to interested readers. The value of the mechanical methods was stressed as worthy of further investigation, and suggestions were made for increasing cooperative exchange of information on the use of these methods.

\footnotetext{
1 Cataloging is an input operation.

2 Using a catalog to locate desired material is an output operation.
} 
The panel on the last day, led by John W. Mauchly, consisted of Robert A. Fairthorne, C. Dake Gull, Calvin N. Mooers, Herman Skolnik, and I. A. Warheit. The panel's topic was "What extrapolation" can be made to larger systems from experience with small collections?" The answer: "Not much." Mr. Gull gave a general review of the needs of larger systems for information storage and retrieval, while the other members of the panel each brought up special problems requiring solutions. Their views may be summed up in Mr. Fairthorne's observation that subjects change when they get larger and systems have to change with them. This means either major adaptation of a small system to the changes caused by growth, or a complete switch to a new system after a certain point-a "sound-barrier" point in information retrieval. The experiences described suggested that the more rugged course was almost unavoidable. With a little system, one has little problems; with a big system, one has big problems; and appar-

3 Appropriation or forced carry-over. ently the two sets of problems are not related closely enough for there to be any significant carry-over from the solution of one to the solution of the other.

The setting for the meeting in Bethlehem was a beautiful one. The facilities of Lehigh University are practically perfect for a group of this size. The hard work of the committee, Lea M. Bohnert, Claire Schultz, Robert S. Taylor, and Isaac D. Welt, in arranging the program and other activities made possible a highly successful meeting. Mr. Taylor, local chairman, not only kept things going smoothly but, when called upon to take over in the emergency caused by the absence of the banquet speaker, turned in a performance as toastmaster worthy of an Oscar or Emmy. The pinchhit program by the ADI officers at the banquet was highly entertaining. The possibility of holding next year's meeting in California is being explored. If the next is as good a conference as this one the organization should gain a strong West Coast representation, perhaps enough for a second local chapter.

\section{Oberly Memorial Award}

Entries are being accepted for the Oberly Memorial Award made every two years by ALA for the best bibliography in the field of agriculture or related sciences. The current award, to be made at the 1961 ALA Annual Conference in Cleveland, is for a bibliography by a U.S. citizen issued in 1959 or 1960 . Final entry date is March 15, 1961.

Seven copies of the bibliography, together with a letter stating that the author is a U. S. citizen, should be sent to Francis P. Allen, Oberly Memorial Award Chairman, University of Rhode Island Library, Kingston. Copies will be returned after the competition if so requested at time of submission.

The award, which consists of income from a fund of about $\$ 1,200$ interest for two years, was established in 1923 by colleagues of Eunice Rockwell Oberly, late librarian of the Bureau of Plant Industry, U. S. Department of Agriculture.

The winning bibliography in 1959 was Literature of Agricultural Research by J. Richard Blanchard and Harald Ostvald, published by the University of California Press, Berkeley, in 1958. 